\title{
Discussion on Common Electricity Stealing Methods and Preventive Measures of User Electric Energy Measurement
}

\author{
Liu Xiao', Cao Huijie ${ }^{1}$, Shan Jia ${ }^{1}$, Cao Huiyan ${ }^{1}$, Yang Yingying, Wei Hua ${ }^{1}$, Jiang Ling ${ }^{2}$, Xu \\ Jianchun $^{2}$, Su Hainan ${ }^{2}$, Jin Jingxin ${ }^{2}$ \\ 1. Fushun Power Supply Company, Liaoning Electric Power Company Limited, State Grid, China. \\ 2. Dandong Power Supply Company, Liaoning Electric Power Company Limited, State Grid, China
}

Keywords: power supply company; electric energy measurement; electricity stealing; preventive measures

\begin{abstract}
In order to cope with the problem of electric power stealing in the power supply company for a long time, according to the influence factors of the accuracy of the electric energy measurement, from the four aspects of current, voltage, phase and installation connection, several common ways of stealing electricity in electric energy metering devices are summarized in detail. Combined with the experience of years of practice, this paper studies and proposes a variety of technical measures to prevent electricity stealing, reducing the loss of electric energy measurement in the metering device and effectively improving the economic efficiency of power supply company.
\end{abstract}

\section{Introduction}

Due to the trend of economic interests, electric energy was stolen by some units or individuals who have taken modified technology measures. The common way of theft is to take various means to avoid the accurate measurement of the electric energy metering device, to achieve the purpose of not counting or less counting the electric energy, and reaching no or less electricity charges. The problem of illegal electricity stealing has always been an important constraint for the accurate measurement of electricity and the development of electricity charge collection. Not only the legal rights and interests of electric energy operation of power supply company has been serious damaged, but also the illegal electricity theft has a great impact for security, which will bring a major threat to the safe use of electricity for the residents. In addition, with the further escalation and development of the intelligent automation technology of illegal electricity theft, there are even a number of "experts" specializing in the research of illegal electric power metering devices, which makes the illegal electricity theft still more serious. Therefore, combined with the years of work experience of electric energy measurement and inspection practice, the common methods of electricity stealing are summed up, and the targeted protective measures are taken to eliminate or reduce the illegal electricity theft, and the reliability of safe power supply of the power supply company is improved. It is very meaningful for the application of engineering practice ${ }^{[1]}$.

\section{Common Electricity Stealing Mode of Electric Power Users}

From the calculation formula of active power, it is known that the measurement of electrical energy consumption is the product value of voltage, current, power factor in power system and time parameter. The purpose of stealing electricity will be achieved when any factor between the three mentioned above is changed. In addition, the purpose of stealing electricity will be achieved when unmeasured power supply lines are privately built for power supply. Therefore, common electricity stealing mode of user power measurement will be analyzed by the author from current, voltage, phase, and installation of wiring.

\subsection{Interruption or division current of the stealing behavior}

In order to achieve the purpose of stealing electricity illegally, the current signal in the electric 
energy metering circuit will not be collected accurately, because the electricity stealing users often change the correct connection mode of the current metering circuit of electric energy meter, or modify the internal wiring by changing the current transformer's (TA) variable ratio and polarity (For example, adding a short-circuit coil or a shunt circuit, etc.). The purpose of electric energy meters without or less electricity is realized because there is no current or only part of current passing through the current coil in the energy meter.

\subsection{No-voltage or under-voltage of the stealing behavior}

By changing the normal connection mode of the voltage metering circuit of the electric energy meter, or by destroying the voltage metering circuit by external force, it causes the problems of open circuit and bad contact, even larger resistance will be connected in voltage metering circuit and so on. All of these cause the voltage metering circuit to fail. The purpose of electric energy meters without or less electricity is realized because no-voltage or under-voltage in the voltage metering circuit of energy meter ${ }^{[2]}$.

\subsection{Phase-shifting of the stealing behavior}

The measuring principle of the electric energy meter will be used by the users' electric power stealing. By changing normal connection mode of the metering circuit, the voltage and current connected to the electric energy meter coil are not matched with the voltage and current consumed by the users in the amplitude and phase. The normal phase relationship between the current and the voltage in the electric energy meter coil is changed by changing the wiring, which leads to the slow speed of the energy meter and even the reversal problem. For example, for low-voltage three-phase three wire connection users, the power supply department usually uses a three-phase two element electric ammeter to measure. In this energy metering system, from the principle of metrology, no matter whether the three-phase load is symmetrical, it can be correctly measured. But if the inductive load is connected between the A phase and the ground (Such as, no load electric welding machine and so on), the metering system will be able to slow down the speed of the electric energy meter. In addition, in the three-phase two element power metering system, only the A phase element and the $C$ phase element, that is, the $B$ phase load current in the power supply system does not pass through the measuring element of the electric energy meter. If the single-phase load is directly connected between the B phase and the ground, then the B load will be completely lost and not measured.

\subsection{Use the defect on the wiring of the electric energy meter to steal electricity}

In the process of installing the energy meter, the anti-stealing electric seal is added to the junction box of the electric energy meter by the power supply department, in order to ensure that the energy meter can run in the normal condition, and the electric energy measurement can be carried out correctly. However, from a large number of engineering experience, it is very easy to reverse the ensealed electric energy meter. Take the single-phase electric energy meter as an example, if the phase and zero line of the single-phase electric energy meter are misplaced, it is equivalent to reverse the dotted terminals of the current and voltage coils at the same name. In this way, the phase and the electric quantity of the 2 measuring coils of current and voltage are not changed. As long as the load of electric side connection is correct, the electric energy meter can be positive rotated and measured correctly. If the load is repeatedly grounded, this part of the load current will not pass through the current coil, resulting in it being unable to be measured. Because of the measurement error, the purpose of stealing electricity can be achieved without prying the anti-stealing electric seal.

\section{Technical Measures to Prevent Illegal Electricity Stealing}

After carefully analyzing and summarizing the related cases of electricity theft and combining with personal experience, this paper sums up the technical measures to prevent the illegal electricity stealing in the work of electric energy measurement. Specific performance is in the use of special 
metering box, the use of bidirectional metering or reverse stop type meter, the use of anti-prizing seal and so on.

\subsection{Use special electric energy metering box or meter box}

Special metering box or meter box should be adopted by low voltage power users. That is to say, the special metering box should be adopted for the electric energy metering system with larger capacity and current transformer access circuit, separate meter boxes should be used by the ordinary three-phase users, the centralized meter box should be adopted by the single phase centralized residential users, and for residents with relatively scattered geographical location, a metering meter box should be installed at the users center according to the reasonable partition of the actual power supply network. In order to realize illegal electricity stealing, primary or secondary equipment of the electric energy metering device should be contacted by electric larceny when committing a crime. By changing the connection mode and adding additional equipment, no or less electric power can be achieved. Therefore, the electric thief can be effectively prevented from touching the internal wiring of the metering device by the use of special metering box or electric meter box, thus effectively strengthening the comprehensive protection ability of the metering device itself. In addition, the safety of the electric energy metering box or the meter box can be improved by adding seal in the box door, installing the security guard lock in the door and welding the box door directly to death.

\subsection{Effective measures are taken for connecting conductors between low voltage outlet terminals of transformers and metering devices.}

If the conductor of the low-voltage outlet terminal of the distribution transformer is sealed to the metering device, the act of stealing electricity without meter can be effectively prevented. In addition, when under-voltage method, undercurrent method and phase shift method are adopted in the secondary circuit of mutual inductor, it also has some preventive effect on this kind of electricity stealing ${ }^{[3]}$.

For large power users, the low-voltage metering cabinet (screen) is usually installed in the electricity distribution room of the low-voltage side of the transformer for measuring the energy consumption. The current transformers, voltage transformers and electric energy meters used in the measurement are all installed in the measuring cabinet (screen). In order to prevent users from stealing electricity, all primary conductors between low voltage outlet terminals and metering cabinet (screen) should be closed. For power users with smaller power capacity, metering boxes are needed, and the sealed primary conductor is also needed. At the same time, if the measurement mutual inductor and the meter are installed in the different distribution boxes, in addition to sealing primary conductor, the secondary wiring between the measurement mutual inductor and the electric energy meter needs to be transmitted by the armored cable. If ordinary plastics and rubber insulated cables are used, all need to be protected by bushing column.

\subsection{Use anti-prizing seal}

The act of stealing electricity by expanding of the difference by private dismantling meter has been effectively avoided by using the anti-prizing seal. At the same time, it has certain preventive effect for under-voltage method, undercurrent method and phase shifting method for stealing electricity, suitable for power users with various power supply modes and connection modes.

\subsection{Use the new generation of electronic multi-function intelligent energy meter}

Because the electronic energy meter has the advantages of no inversion, minimum value cannot automatically clean up, and the meter parameter cannot be modified arbitrarily, it can effectively prevent the electricity stealing behavior. In addition, the multi-function intelligent electric energy meter has the function of automatically recording events such as loss of voltage, loss of current, current imbalance, reverse phase, parameter setting and so on, which can effectively prevent the occurrence of electricity stealing. 


\subsection{Use bidirectional metering or reverse stop type meter}

Phase-shifting electricity stealing behavior can be effectively prevented when bidirectional metering or reverse stop type meter is adopted. It is more suitable for the electric energy metering of ordinary low voltage users without reverse power supply.

\subsection{Standard electric energy meter installation wiring}

By standardizing the installation and wiring of electric energy meters, the behavior of stealing electricity, such as under-voltage, undercurrent, expanding of the difference and phase shifting, is protected to a certain extent.

\subsection{Use advanced anti electric stealing system}

Use advanced anti electric stealing system (For example, GPRS/GSM and other mobile communication networks is used to be transmission platform for electric energy consumption information.) The automatic meter reading system is popularized in the process of rural power grid transformation. The real-time monitoring and scientific dispatching management of users' electricity consumption(especially high power users) are carried out, in order to accurately grasp the user's power consumption information, and promptly discover illegal electricity stealing behavior, reduce the power supply company stealing electricity loss. At the same time, the safety and reliability of power supply can be improved and ensure users' safety and reliability, energy saving, economic efficiency and stable electric energy consumption.

\section{Conclusions}

Anti-stealing electricity is a continuous, long-term and complex system engineering. It is an important content in the electric energy metering and research on audit work. In the operation and management of the actual electric energy measurement, the power supply company should constantly improve the supervision mechanism of the safety electric energy use, strengthen the upgrading and reform of the metering system technology, and increase the power of the use of electricity, in order to prevent and deal with the endless methods and means of stealing electricity. In this way, the power supply has been ensured with higher safety and reliability, illegal electricity stealing behavior will be eliminated or reduced, and the economic benefits of power supply company's operation will be effectively improved.

\section{References}

[1] Hu Hanmei. Wang Yuanlong. The Analysis and Discussion of Electricity-stealing and Precaution Method [J]. Electrical Measurement \& Instrumentation, 2004(03):54-56.

[2] Wang Guanghui. Wang Hongyan. Yang Yuhong. Electric Power Sales and Management of Power Use [M]. Beijing: China Electric Power Press, 2007.

[3] Han Gujing. Yin Xiaogong. Qin Liang. A Novel Technique of Preventing Electricity-stealing in Current Method For Electric Power Measuring Equipment [J].Electrical Measurement \& Instrumentation, 2007,44(502):29-33.

[4] Shao Yanying. Several Problems in Installation and Operation Management of Electric Energy Metering Devices [J]. Science\& Technology and Enterprises, 2013 (22).

[5] Zhai Lei. Li Yuzhu. Analysis and Processing of Problems on-the-spot of Electric Energy Metering Device [J]. Compilation of the Twelfth Outstanding Papers of the Shandong Institute of Electrical Engineering[C], 2011. 